\title{
O Compromisso da Abem com a Residência
}

\author{
Abem's Commitment to Residency
}

Denise Herdy Afonso ${ }^{I}$

Gostaria de discutir com o leitor da Rbem a importância do preceptor numa sociedade que muitos conceituam como "sociedade intensiva em conhecimento" (Demo, 2009), a qual se caracteriza, ao lado da "globalização" do acesso à informação, por uma crescente demanda por aprender. Nesse contexto, inclui-se a expectativa sobre produção e uso de tecnologias em educação, em particular na educação a distância.

Em nosso país, políticas públicas cumprem o seu papel de orientar as diretrizes de cuidado, educação e gestão na saúde.

Para o cuidado, organizamos práticas de atenção à saúde a partir dos princípios e diretrizes do Sistema Único de Saúde, em destaque na Lei 8.080, de 19 de setembro de 1990: equidade, integralidade e universalidade do cuidado.

Na educação, ao buscarmos as orientações para a formação dos profissionais da saúde no nível de graduação, encontramos as Diretrizes Curriculares Nacionais de Graduação dos cursos das áreas da saúde, que, desde 2001, assumem como competências gerais esperadas desses egressos: a atenção à saúde, comunicação, tomada de decisões, administração e gerenciamento, liderança e educação permanente.

Na busca por uma integração entre as diretrizes de cuidado e as de graduação em saúde, o governo federal, desde 2005, iniciando suas ações pelo Pró-Saúde, vem implementando políticas de incentivo ao redirecionamento da atenção priorizando a organização do sistema a partir da Atenção Primária à Saúde, com consequente deslocamento do ensino para a rede assistencial pública. Em seguida, ainda com foco na graduação e para dar continuidade à proposta de integração ensino-serviço, inicia-se o PET-Saúde, com o objetivo de fomentar a formação de grupos de aprendizagem tutorial em áreas estratégicas do SUS.

Na pós-graduação, inicialmente na Residência Médica e em seguida na Residência Multiprofissional e em Área Profissional, os Ministérios da Educação e da Saúde, em decisão conjunta, instituem o Programa de Incentivo à Formação de Especialistas em Áreas Estratégicas, o Pró-Residência. Em seu objetivo geral, destaca-se a integração de ações, uma vez que a definição das áreas estratégicas e das regiões priorizadas considera a demanda local de saúde identificada pelo gestor local.

Cabe destacar que todos os dispositivos governamentais citados necessitam ensinar e gerir suas práticas para a adequada implementação de profissionais da saúde aptos a cuidar. A interseção da resolutividade de todos os programas passa, portanto, pelo preceptor qualificado para a ação, destacando, dessa forma, a importância do desenvolvimento dos preceptores que atuam nas graduações em saúde e que, por vezes, são os protagonistas da formação nos programas de Residência.

REVISTA BRASILEIRA DE EDUCAÇÃO MÉDICA $151 \frac{12(2): 151-152 ; 2012}{36}$

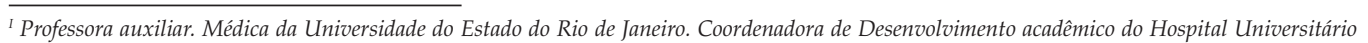
Pedro Ernesto; Coordenadora geral do Projeto Preceptoria ABEM. 
Definido esse contexto, podemos perceber porque colocamos o preceptor como figura estratégica, ocupando lugar decisivo, central na constituição e funcionamento de nossas redes de educação e saúde. Dificilmente o preceptor de hoje será como o do século passado. Mudam as práticas, os conceitos, os desafios, a expectativa da sociedade, as demandas de ensino e aprendizagem. Ser preceptor hoje é saber renovar, reconstruir, refazer a profissão. É deparar-se com o desafio do domínio de conteúdos que se tornam obsoletos em velocidade assustadora e necessitam de atualização permanente. É desenvolver suas habilidades técnicas específicas em consonância com os padrões de acreditação utilizados nas auditorias das diversas Sociedades. Mas, acima de tudo, ser preceptor é enfrentar o desafio de cuidar da aprendizagem, não como dono desse processo. O desafio que se coloca é praticar a preceptoria sustentando sua ação de educador, compreendendo que educar é um processo reconstrutivo, de dentro para fora, em direção à autonomia (Maturana, 2001) e, complementando com Paulo Freire, "educar é exercer influência sobre o aluno de tal modo que ele não se deixe influenciar".

A Associação Brasileira de Educação Médica (Abem), coerente com sua missão institucional de atuar pela "(...) formação de um profissional capaz de atender as necessidades de saúde da população (...)" e direcionada pela visão estratégica de "Ser reconhecida como a principal protagonista de melhorias na educação médica brasileira, (...) influenciando as políticas públicas de educação e saúde (...)", se insere no desafio de reescrever o ofício da preceptoria e inicia, em 2012, um projeto nacional para o desenvolvimento de competências pedagógicas de preceptores, inicialmente direcionado para a Residência Médica.

Com a meta de chegar a 12 estados da federação localizados em regiões estratégicas devido à carência de especialistas e pela demanda de fixação de médicos, de acordo com dados do Pró-Residência (Acre, Bahia, Ceará, Goiás, Maranhão, Mato Grosso, Mato Grosso do Sul, Pará, Pernambuco, Rio Grande do Norte, Roraima, Tocantins), e alcançar 320 preceptores de Residência Médica, a Abem inicia uma verdadeira "onda" que, esperamos, se propagará em todas as direções e para os programas de Residência Multiprofissional e em Área Profissional da Saúde, trazendo "efeitos colaterais" no exercício da preceptoria, em especial do Internato, considerando que a maioria dos preceptores envolvidos nos cursos tem atuação também na graduação.

Uma ação de tamanha amplitude só se concretiza com a participação de toda a comunidade de educadores e gestores, que, sensibilizados, direcionam suas ações para a valorização da preceptoria, professores que, inseridos na rede de serviços, percebem o potencial formador de profissionais comprometidos com suas práticas de cuidado e destes preceptores em ato, que, para além da atenção à saúde, assumem o compromisso de atuar na educação de nossos alunos e jovens profissionais da área.

Na trajetória dos cursos, nos caminhos da preceptoria, durante o processo de reflexão crítica sobre sua prática profissional, encontramos, nos protagonistas desse ofício, preceptores ora "espantados" de se reconhecerem educadores, ora "orgulhosos" de estar no centro do processo de formação, e sempre "disponíveis" para aplicação imediata do aprendizado que vivenciam.

Ao final desse caminho, teremos construído o perfil do preceptor, sua expectativa em relação aos residentes que desejam formar, seus desafios para ensinar no contexto atual da rede da saúde e suas propostas de reorganização das práticas de formação. No entanto, mais do que médicos especialistas conscientes de seu ofício, esperamos constituir uma rede colaborativa de profissionais unidos pela identidade coletiva de ser preceptor. 